\title{
An Unexpected Cause of Halitosis
}

\author{
Major J D C Bennett
}

BSc, FRCS, DCH, RAMC

Senior Specialist in Otolaryngology

${ }^{*}$ Queen Elizabeth Military Hospital Stadium Road, Woolwich, London SEI8 4QH

SUMMARY: A case of long standing halitosis due to a nasal foreign body is described, and the causes of halitosis are reviewed.

\section{Introduction}

The causes of halitosis, both real and imaginary, are many, but in paediatric practice the presence of a nasal foreign body must always be suspected. In the case under consideration, unusual because the expected nasal obstruction, irritation and rhinorrheoa were absent, the removal of a washer relieved halitosis of five year's duration.

\section{Clinical Presentation}

A six year old girl who had undergone adenotonsillectomy 18 months earlier was admitted routinely for insertion of tympanostomy tubes for persisting secretory otitis media. On closer questioning however it emerged that her main problem was halitosis of five years' duration. ENT examination was unremarkable. revealing good nasal airways and no rhinorrheoa or post nasal drip, and the lungs were clear on auscultation. Sinus X-rays revealed a large round radio-opaque body, as illustrated in Figure 1. At operation this was found to be a severely corroded $1.5 \mathrm{~cm}$ diameter washer firmly impacted in the left side of the nose and removed only with difficulty. Uneventful post-operative recovery followed, with resolution of the halitosis.

\section{Discussion}

Halitosis may be real or imaginary, and is associated in the latter case with depression, hypochondriasis, schizophrenia and temporal lobe epilepsy'. In genuine cases, chromatography of exhaled breath shows three peaks, the highest being for hydrogen sulphide, followed by methyl mercaptan, and then dimethyl sulphide $^{2}$. There are wide subjective variations between observers and thresholds of detection, but methyl mercaptan is the most objectionable odour and is detectable at the lowest concentration. The compounds mentioned are produced by a varicty of Gram negative bacteria acting on proteinaceous materials such as degenerated epithelial cells and leucocytes. This can occur for a variety of reasons.

\section{Disorders of the Oral Cavity}

The majority of causes of halitosis fall into this group. Normal saliva generates an unpleasant odour after it has *Now British Military Hospital, Rinteln, BFPO 29

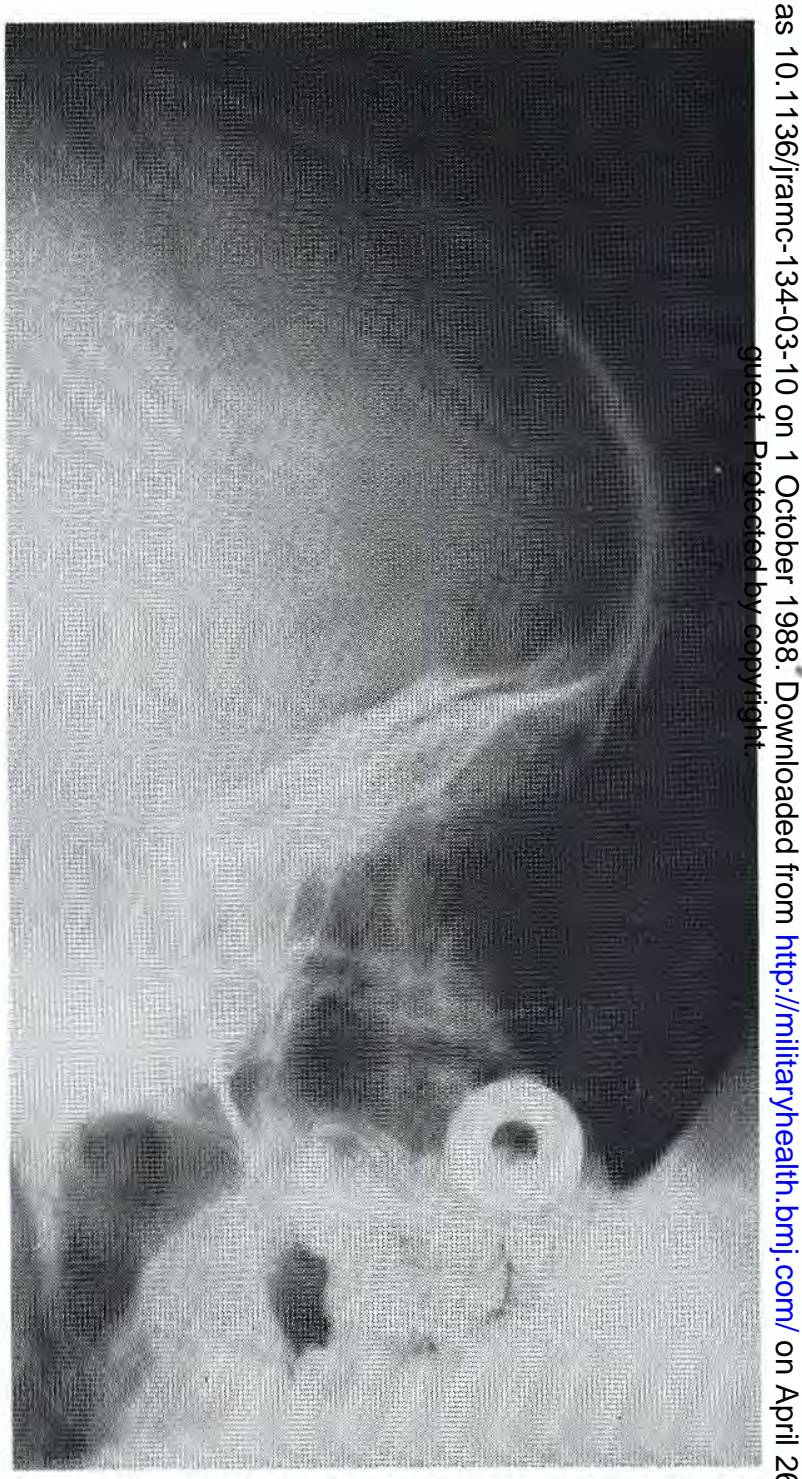

Figure 1. Lateral skull X-ray showing washer lodged in the nose. 
been incubated for an hour ${ }^{3}$. In the presence of periodontitis, this reaction occurs more rapidly as volatile substances are produced through the putrefactive action of micro-organisms on exfoliated epithelial cells, leukocytes and mucopolysaccharides. The process is accentuated when degenerative and inflammatory disorders are present. Halitosis originating in the oral cavity may be associated with poor oral hygiene, dental plaque and caries, gingivitis, stomatitis, periodontitis, hairy tongue and oral carcinoma.

\section{Disorders of the Upper Respiratory Tract}

Mouth breathing due to nasal obstruction causes the volume of saliva in the mouth to fall due to evaporation, thus diminishing its cleansing action. In addition, secondary infection within the nose, tissue necrosis and lack of normal drainage provide opportunity for the production of malodorous compounds.

\section{Disorders of the Lower Respiratory Tract}

Halitosis is sometimes the first symptom of lung abscess, but breakdown of tissue and secondary infection by anaerobic bacteria associated with carcinoma of the lung, bronchiectasis, necrotising pneumonitis and empyema may all be associated with its occurrence.

\section{Disorders of the Gastrointestinal Tract}

There is controversy about whether or not conditions originating below the gastro-oesophageal junction can cause halitosis and it is thought that in such circumstances odour is detectable only during retching or vomiting, as normally the oesophagus is collapsed ${ }^{4}$.

\section{Drugs and Food}

Drugs, including lithium salts, penicillamine, griseofulvin and thiocarbamide, may alter the senses of taste and smell, causing subjective halitosis. Various foods are metabolised to produce volatile fatty acids other malodorous substances excreted by the lungs (dimethyl sulphoxide for example causes the breath smell of stale oysters), while studies have shown that $9 f$ garlic is introduced into the peritoneal cavity or eve्g rubbed into the soles of the feet it can produce detectable odour on the breath ${ }^{5}$.

\section{Conclusion}

The case discussed here was unusual because the expected accompaniments of a nasal foreign body su雨 as rhinorrhoea and nasal obstruction were not prese thanks to the central hole in the washer. Nevertheless enough stasis and infective necrosis was produced over the five year period to cause unacceptable halitosis. $\Phi$ illustrates well the aphorism that unusual presentations of common conditions are more common than unusug conditions, and also the value of a careful history - th foreign body went undetected eighteen mont previously when adenotonsillectomy was performed.

\section{Acknowledgement}

The helpful advice of $\mathrm{Lt} \mathrm{Col} \mathrm{T}$ Bouchier-Hayes RAMC is gratefully acknowledged.

\section{REFERENCES}

1. Pryse A and Phillips W. An Olfactory Refergnee Syndrome. Acta Psychiatr Scand 1971; 47: 484-510.

2. TONZETICH J. Direct Gas Chromatographic Analysis $\Phi_{f}$ Sulphur Compunds in Mouth Air. Arch Oral Biol 197 14 . 587-597.

3. BERG M, BURRILl D Y and FosDdick L S. Chemical Stwi in Periodontal Disease. J Dent Res 1947; 26: 67-71.

4. AtTIA E Let al. Halitosis. Can Med AssocJ 1982; 126: 1285.

5. CROHN B B and Droso R. Halitosis. JAMA 1941; 1 Ri 2242-2245. 